\title{
COMMENTARY
}

\section{THEORY AND PRACTICE OF INTERNATIONAL ENVIRONMENTAL NEGOTIATIONS ${ }^{1}$}

\author{
Helena Varkkey
}

\begin{abstract}
This commentary reviews the theory and practice of international environmental negotiations among states for management of shared environmental resources to overcome the free-riding problem. Despite a lack of formal enforcement mechanisms, states generally comply with their environmental obligations once established. The negotiation process is thus seen as the most significant factor in enacting environmental policies. To work towards the success of multilateral environmental policies, the paper recommends states to make use of a combination of approaches (structural, behavioural, strategic, integrative) and strategies (driving, braking, trade-offs) to frame negotiations that would 'fall forward' to its own improvement in their later stages. At the same time, it is important to create positive-sum outcomes for parties involved to increase the likelihood of states fulfilling their obligations in the long run. Trade benefits and restrictions may be used as a tool in negotiations but their impacts remain largely controversial and debatable among many scholars.
\end{abstract}

Keywords: Negotiation theory, environmental negotiations, environmental politics, environmental regimes, environment and trade

\section{INTRODUCTION}

The shared environment is generally understood as a common property resource, meaning that access to the resource is free for all. In such common property, there is a tendency that each user will use (and over-use) as much of the resource as he or she needs, with little or no regard for how this may affect other users. ${ }^{2}$ In such scenarios, all users 
(in this case, states) will benefit from being free-riders (up to a certain point!). ${ }^{3}$ As depicted popularly in Prisoner's Dilemma ${ }^{4}$ scenarios, if other states choose to undertake abatement measures, there would be opportunities to free ride. If other states pollute, there would be no losses incurred. ${ }^{5}$ Therefore, states will tend to over-use the resource, or emit more pollutants than is efficient. States are thus at once both the source and victim of the problem. ${ }^{6}$ This is known as the tragedy of the commons.

This tragedy is often accounted to the lack of international mechanisms to manage the shared resource. Sustainable use of the commons, and thus collective well-being should be able to be increased if states cooperate in managing the shared environmental resources ${ }^{7}$ and solving international environmental problems. Therefore, often International Environmental Agreements (IEAs) are called upon to manage such common property problems and to change inefficient outcomes. IEAs generally outline the shared responsibilities of states pertaining to the management of the shared resource.

Once states accede to such IEAs, it has been observed that most states will comply with most of their obligations most of the time. This cannot be accounted to the presence of any formal enforcement or conflict resolution mechanisms. ${ }^{8}$ Chayes and Chayes ${ }^{9}$ note that "not only are formal enforcement mechanisms seldom used to secure compliance with treaties, but they are rarely even embodied in the treaty text." Furthermore, these mechanisms are rarely able to be enforced, given that there does not currently exist an adequate form of international 'government' to do so. ${ }^{10}$ Instead, the concept of diffuse reciprocity is seen as an important determinant of compliance, ${ }^{11}$ where states are pressured to comply with their obligations out of the understanding that they may have to deal with other members of the treaty at some time in the future and their present violations may affect goodwill in the future. ${ }^{12}$

Therefore, it can be understood that states decide whether or not to accede to a treaty with the understanding that if they do accede, they will comply with the agreement. ${ }^{13}$ Chayes and Chayes ${ }^{14}$ describe this behaviour as 'bargaining in the shadow of the law', even though the international legal system is not equipped to enforce such treaties. Therefore, the issue here seems not to be whether the states will fulfill 
its obligations once it signs the agreement, but the process of making the agreement attractive for states to want to sign it in the first place. ${ }^{15}$ Compliance will generally follow.

This paper thus reviews the extant literature on the theory and practice of 'getting states to agree to cooperate', or in other words, the theory and practice of international environmental negotiations. First is a discussion on the circumstances under which states would be motivated to engage in negotiations towards cooperative outcomes. Following that is a review of the general three-phased negotiation process of diagnosis-formula-detail. The third section touches on the various negotiation approaches often used by parties in this process, covering the structural, strategic, behavioural, and integrative approaches. The fourth section expounds further on the strategic approach, detailing the three popular strategies (driving, braking, and tradeoffs) often used in international environmental negotiations. The final substantive section briefly discusses political economy issues in negotiation, pertaining to the pros and cons of the use of economic strategy. As a whole, this paper highlights the importance of an effective negotiation process to ensure efficient outcomes on the management of shared resources.

\section{MOTIVATIONS FOR INTERNATIONAL ENVIRONMENTAL NEGOTIATIONS}

States affect and are affected by the actions of other states in various ways. Cases of unidirectional externalities involve upstream polluting states (either one or many) and downstream suffering states (again, either one or many). Cases of regional or global reciprocal externality involve group of states (or all states) which are "both the source and victim of an environmental problem." 16 The existence of various combinations of 'source' states and 'victim' states implies winners and losers in a certain environmental issue. Indeed, Zartman ${ }^{17}$ has argued that "the very existence of a problem is prima facie evidence that some parties benefit from it and have an interest in its continuation."

Attempts to manage or solve such environmental problems therefore would imply a changing of this dynamic, often involving winners becoming losers and vice versa, which would be highly unattractive to certain states. However, despite all the odds stacked against it, we 
see that a substantial number of IEAs have been agreed upon. ${ }^{18}$ The International Environmental Agreements Database Project, which monitors such agreements, has in fact recorded a steady increase of IEAs over the years, especially during the decade of 1990 to 1999 (see Figure 1). Several scholars have attempted to explain the motivations for states to agree to international environmental negotiations and its resulting agreements.

Figure 1: Annual Count of New Agreements ${ }^{19}$

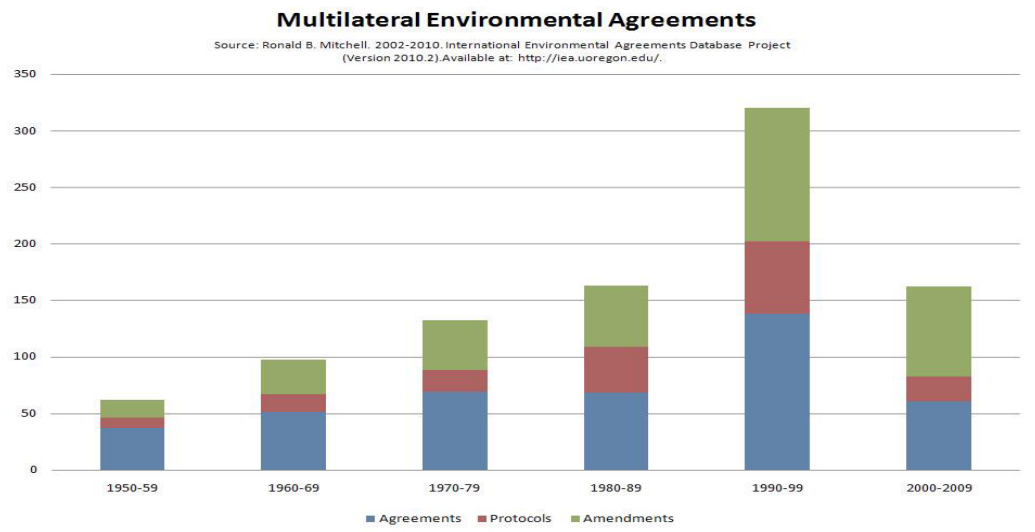

Zartman $^{20}$ identifies 'ripe moments' as strong motivators for states to negotiate. This condition happens when involved parties recognize that the status-quo is not a win-lose situation, but instead it is lose-lose. ${ }^{21}$ This is generally depicted as a recent or impending catastrophe that illustrates a mutually hurting stalemate (the inability of either party to prevail). Catastrophes are especially important in shifting the interests of parties involved, by converting former opponents of action to proponents in an effort to resolve the predicament that led to the catastrophe. ${ }^{22}$ The moment becomes especially 'ripe' when, in addition to the catastrophe, there also exists an authoritative spokesperson and a plausible solution. Without these features, states would not be interested in engaging in negotiations. Zartman $^{23}$ thus notes that preemptive problem solving would be difficult in international environmental negotiations, and would often lack the drive and urgency of negotiations in the wake of a catastrophe. 
This would explain why climate change negotiations have been relatively unsuccessful; it is lacking a real catastrophe, and climate change skeptics continue to play down the possibility of an impending one. However, waiting for a catastrophe to begin negotiations may be more costly in the long run, and more importantly, may only be able to kick-start action when it is already much too late. ${ }^{24}$

A less pessimistic Chasek ${ }^{25}$ believes that states can be brought to the table without the need for a catastrophe. Chasek stresses on the importance of 'precipitant events' that bring environmental problems to the attention of the international community. Precipitant events could be either (or a combination of) scientific evidence of danger, growing public concerns, or economic repercussions related to pollution or the overexploitation of natural resources. The severity of the precipitants and the role of external actors (NGOs, scientific community, the public, and the media) in pressuring governments to address the issue often influence the length of time it takes for the international community to determine that multilateral negotiation is the best policy option. International environmental negotiations thus will begin when governments recognize that scientific evidence, public concerns, and economic repercussions of a particular environmental issue is serious enough, is global or regional in nature, cannot be solved on a unilateral level, and may be best addressed through multilateral negotiation.

Sometimes, interested states (a 'motor group') can expedite this process by encouraging the creation of 'epistemic communities ${ }^{26}$ ' either within their own states or across states. ${ }^{27}$ These epistemic communities can help focus the attention of the international community on a particular environmental issue, and shape its perception towards that issue. It has been suggested by Maler that the 'Bayesian Approach' may be adopted by such motor groups and epistemic communities to gain the support of other states to engage in negotiation. This approach stresses two things; the irreversibility of such environmental change, and the probability that new information (of the consequences of inaction) may surface in the future. ${ }^{28}$ It is in the spirit of the 'precautionary principle' defined in Principle 15 of the 1992 Rio Declaration on Environment and Development. It states the following: "Where there are threats of serious or irreversible damage, lack of scientific certainty shall not be used as a reason for postponing cost-effective measures to prevent environmental degradation." ${ }^{29}$ The approach has been helpful in kick- 
starting negotiations over matters like climate change and preservation of biological diversity (eg. whaling) to avoid future extinction. ${ }^{30}$

\section{THE PROCESS OF INTERNATIONAL ENVIRONMENTAL NEGOTIATIONS}

Both approaches discussed above on what motivates states to negotiate rest on at least one fundamental aspect: parties who agree to negotiate agree that entering into negotiation will serve their respective purposes better, compared to unilaterally attempting to achieve their objectives. ${ }^{31}$ Starting from recognition and acceptance by governments, Zartman has identified a three-phased process that international environmental negotiations generally go through. He calls this the 'diagnosisformula-detail' process: the scientific preparation of the diagnosis of the problem, crystallizing a formula that defines the problem in a resolvable way, and finally the translation of the formula into coherent details for implementation. ${ }^{32}$

The diagnostic phase involves the series of events and behaviours observable before the actual negotiations begin. Alfredson and Cungu' describe the diagnostic phase as the phase where "parties evaluate an issue area, ascertain the appropriateness of negotiations, attempt to signal their willingness to negotiate with the other party and test the other party's willingness to engage in and sincerity of commitment to possible negotiations." 33 An important element to be determined at the pre-negotiation stage is the 'conductor' or 'mediator' role; whether the negotiations would be state-led (conductor), or led by an intergovernmental body (mediator).

In issues with strong 'motor groups' as mentioned above, the conductor role is usually played by one state or a group of states. This concerned state or group or states may initiate the process by preparing a draft treaty that addresses the issue of concern. ${ }^{34}$ The treaty is then proposed to a larger group of states. However, such state-centered negotiations may not be very effective as the conductor will often be perceived by other states as 'tainted' with its own interests and partiality. ${ }^{35}$

An alternative would be for states to raise the issue at a meeting of an intergovernmental body, from which states can take the decision to embark on international negotiations. ${ }^{36}$ This intergovernmental body or 
its representative (secretary-general, conference chair, and secretariat) thus becomes the designated 'mediator' of negotiations on the issue. This arrangement is usually preferable to state-led negotiations as this mediator is not supposed to be partial to any sovereign country and should not have its own interest-related agenda. Its role would thus be to encourage an outcome of the negotiations that provides "both the largest pie possible and also the largest shares of it for each party." ${ }^{\prime 37}$ The existence of this independent mediator is useful in providing order to the proceedings, facilitating agreement while at the same time enabling parties to effectively uphold their interests. ${ }^{38}$

Following that comes the crystallizing stage. The first step in crystallizing the formula for addressing the problem is framing, or determining how the problem is described or perceived. ${ }^{39}$ An effective mediator should frame the problem in such a way that it creates an "atmosphere conducive to further discussions and negotiations." 40 For example, presenting the issue to the negotiators as a "mutual problem to be solved together" ${ }^{41}$ while 'maximizing gains' (instead of minimizing losses) may increase the likelihood of the parties reaching a negotiated settlement. At this stage, negotiations would generally consist of a series of concessions that would be useful in signaling their own intentions, learning about their opponents' positions and encouraging movement in their opponent's position until both parties settle on an agreeable formula. ${ }^{42}$

Effective framing and communication between the parties involved will hopefully result in a formula that 'falls forward', as Zartman ${ }^{43}$ describes. This means that the formula calls for its own improvement in the detailing stage. As such, the output of a first negotiation round would generally be a framework agreement consisting of "statements of intent, codes of conduct, or differential obligations, exceptions and reservations (discussed below), which are then gradually turned into binding obligations" 44 at the detailing stage. A good example of this process at work is the Vienna Convention on the Ozone Layer of 1985 where the initial formula was 'a loose framework agreement in exchange for research and a commitment to a workshop and a future conference'. It was designed with the intention to bring both camps (for and against the 'total ban' of CFCs) to the table in the earlier stages, serving as a prelude to the more detailed 
and prescriptive Montreal Protocol on Substances that Deplete the Ozone Layer in $1987 .{ }^{45}$

\section{APPROACHES TO INTERNATIONAL ENVIRONMENTAL NEGOTIATIONS}

As discussed above, multilateral negotiations are often shaped by "scientific uncertainty, the complexity of the issues and a wide range of actors and interests." ${ }^{6}$ Thus, parties will generally commence negotiations to further or defend their respective corner of interests. ${ }^{47}$ Faced with conflicting interests, effective negotiations therefore often involve creating novel solutions with an interest-based opposition, an attempt to combine conflicting points of view into a single decision. ${ }^{48}$ Four core approaches to negotiation, namely the structural, strategic, behavioural, and integrative approaches, have been identified by Zartman and are discussed respectively below.

The structural approach to negotiations considers structural features as the most important determinant of outcomes. These include considerations the distribution of means or capabilities among parties before negotiations commence. ${ }^{49}$ Therefore, outcomes of a negotiation are seen to be deterministic (a priori) once the structural features of each negotiation are understood. This approach paints a conflict scenario whereby opponents in the negotiation maintain incompatible goals. The structural approach would predict that the ability of each party to secure their individual goals through the negotiation process would depend on the relative 'power' of that party (the possession of 'strength' or 'resources', or more importantly, the ability to 'win' the biggest slice of the 'pie'). ${ }^{50}$

While the structural approach emphasizes the importance of capabilities in the negotiation process, the strategic model on the other hand focuses instead on the ends (payoffs) in determining negotiation outcomes. ${ }^{51}$ This is closely related to rational choice models, where negotiators are considered rational decision makers who know the alternatives available to them. They would thus make calculated choices that will maximize their ends. Each negotiator has a unique 'incentive structure', where a set of costs is associated with different actions, and each action is measured for its likelihood to produce desired outcomes. ${ }^{52} \mathrm{With}$ this focus on payoffs, the strategic approach 
to negotiations would aim for the maximum calculated zero-sum outcome.

Where the strategic approach assumes that negotiators are featureless, uniformly rational and payoff-maximizing entities, the behavioural approach takes an opposite view by emphasizing human tendencies, emotions and skills. The behavioural perspective dictates that personal motivations of individual negotiators would depend on the individual's position across two dimensions: degree of interest in interpersonal relationships and degree of interest in outcomes. This would result in four typologies of motivational positions: the individualistic, the altruistic, the cooperative, and the competitive. ${ }^{53}$ An individualistic negotiator is concerned exclusively by his or her own well-being and outcomes. Someone with an altruistic orientation is the opposite; he or she is exclusively concerned for the well-being of other parties. A cooperative negotiator is considers the well-being of both negotiating parties. While one with a competitive orientation is motivated by a strong desire to out-do his or her opponent. ${ }^{54}$ Only the cooperative motivational style would aim for win-win solutions, while individualistic, altruistic and competitive positions usually result in win-lose or zero-sum outcomes.

While a zero-sum perspective of negotiation views it as a process of claiming a share of a fixed amount of pie, the integrative approach rejects this 'fixed' perspective and instead promotes the idea of potential win-win situations in negotiations. ${ }^{56}$ Negotiators in this spirit usually explore means to 'expand the pie' by creating value so that there is more for the parties to share. This approach emphasizes the importance of communication, and exchanging information between parties to find commonalities of interests between them. Therefore, an emphasis is placed on developing shared principles about how outputs should be claimed. ${ }^{57}$

The key features of these four approaches have been summarized in the work of Alfredson and Cungu', ${ }^{58}$ as seen in the Table 1. However, as noted in the table, each of these individual approaches to negotiations suffers from certain limitations and constraints. For example, in structural, strategic, and certain behavioural approaches, Alfredson and Cungu'59 notes that "blind attachment to 'winning' all you can from a negotiation regardless of the resulting satisfaction 
Table 1: Adapted from 'Summary of Approaches' ${ }^{55}$

\begin{tabular}{|c|c|c|c|}
\hline Approach & Basic features & Assumptions & Limitations \\
\hline Structural & $\begin{array}{l}\text { Focus on means, } \\
\text { positions, and } \\
\text { power }\end{array}$ & Win-lose & $\begin{array}{l}\text { Lock into positions might } \\
\text { lead to lost opportunity } \\
\text { for mutually beneficial } \\
\text { agreement. Over- } \\
\text { emphasis on power. }\end{array}$ \\
\hline Strategic & $\begin{array}{l}\text { Focus on ends, } \\
\text { rationality, } \\
\text { positions }\end{array}$ & $\begin{array}{l}\text { Win-lose, } \\
\text { existence of } \\
\text { optimal solutions } \\
\text { and rationality of } \\
\text { players }\end{array}$ & $\begin{array}{l}\text { Excludes use of power; } \\
\text { players undifferentiated } \\
\text { in this sense. }\end{array}$ \\
\hline Behavioural & $\begin{array}{l}\text { Focus on } \\
\text { personality traits }\end{array}$ & $\begin{array}{l}\text { More often win- } \\
\text { lose (win-win only } \\
\text { if cooperative), } \\
\text { role of perceptions } \\
\text { and expectations }\end{array}$ & $\begin{array}{l}\text { Negotiating positions } \\
\text { assumed to be wholly } \\
\text { determined by the } \\
\text { negotiator's personality } \\
\text { 'type'. }\end{array}$ \\
\hline Integrative & $\begin{array}{l}\text { Focus on } \\
\text { problem solving, } \\
\text { creating value, } \\
\text { communicating, } \\
\text { win-win } \\
\text { solutions }\end{array}$ & Win-win potential & $\begin{array}{l}\text { Parties should still } \\
\text { recognise and be prepared } \\
\text { for encounters with non- } \\
\text { integrative bargainers. } \\
\text { Time consuming. }\end{array}$ \\
\hline
\end{tabular}

of other parties, can be a poor long-term strategy if it means that the other side will lose its will, or ability to maintain its side of the negotiated agreement." Negotiators who are determined to obtain a win-win outcome may reach a dead end when faced with opponents who will take nothing less than zero-sum. Hence in practice most negotiators make use of a combination of the above approaches during a negotiation. ${ }^{60}$ Negotiators would do well to understand both the means and ends of its negotiating partner, as well as their personality traits for a more integrative outcome.

\section{THE STRATEGIC APPROACH TO INTERNATIONAL ENVIRONMENTAL NEGOTIATIONS}

Most combinations of negotiation approaches often involve some sort of strategic bargaining. As mentioned above, the strategic approach 
places emphasis on the outcomes of a negotiation. ${ }^{61}$ Therefore, states will usually decide the type of strategies employed during negotiation by comparing the (predicted) payoffs they receive if they comply or abstain from the agreement. ${ }^{62}$ Common strategies used by states entering into negotiations include driving, braking and tradeoffs.

A driving strategy is generally pursued by the proponents of an issue to have a particular measure or position incorporated into the final agreement. These proponents are usually convinced that such measures or positions would give them a positive payoff. On the other hand, a braking policy is usually pursued by its opponents in an attempt to oppose such a policy. ${ }^{63}$ These parties are generally convinced that such measures proposed would result in negative (zero-sum) payoffs should they accede. They may also employ braking strategies because they do not have the means to comply with such an agreement. ${ }^{64}$

Tradeoff strategies are important in helping states to address their respective concerns, by trying to make the agreement more attractive for opponent states to sign. ${ }^{65}$ Therefore, while strong driving and braking camps can put negotiations at risk, tradeoff strategies can be incorporated into the options to encourage negotiations continue and not break off. According to Zartman, ${ }^{66}$ there are generally three categories of tradeoffs: the modifying strategy, the exit strategy and the compensation strategy. The following sections will expound on each one of them.

\section{The Modifying Strategy in Negotiations}

The first is the modifying strategy, where opponents can attempt to slow down the effect of a drive, usually by encouraging the negotiating parties to settle for 'sounder' agreements. 'Sounder' agreements usually trade depth for breadth in the content of treaties, normally resulting in vaguely-worded agreements. ${ }^{67}$ While this strategy considerably weakens the agreement's effectiveness, it remains important in that it is a useful strategy to get states to agree on an initial agreement, which later may be encouraged to 'fall forward' towards stronger protocols as discussed earlier.

A good illustration of the modification process in negotiation is the Convention on Environmental Impact Assessment in a Transboundary Context (the Espoo Convention) of 1997. Many states currently require 
some type of Environmental Impact Assessment (EIA), like the United States Environmental Policy Act and the European Commission's Directive 85/337, which are generally meant to ensure that decision makers consider the ensuing domestic environmental impacts when deciding whether or not to proceed with a project. ${ }^{68}$ The convention requires its parties to also assess the transboundary environmental effects of certain actions within their jurisdictions and to notify and consult with potentially affected states about those effects. The convention embodies the international environmental law principle of non-discrimination, which indicates that states should apply the same environmental protections to potential harm in other states that they apply to such harm in their own. ${ }^{69}$

Negotiators for the Espoo Convention used the modifying strategies to create a 'sounder' EIA agreement, as depth was traded for breadth to achieve agreement and maximize participation. For instance, the convention only requires transboundary EIAs for categories of projects that are already listed in their respective domestic legislation. Also, while the convention directs the state of origin to take due account of the EIA, it does not actually require the prevention of any harm by the state of origin. The resulting convention thus did not push states much further than existing domestic EIA regulations, however it did manage to secure almost universal participation. This arrangement would arguably be preferable to no agreement, as at the very least, the convention would be useful as a basis of post hoc determination of compensation owed to the affected state, along the lines of the 'polluter pays principle'. ${ }^{70} 71$

\section{The Exit Strategy in Negotiations}

The second is the exit strategy. Counter-intuitively, exit strategies do not involve the breaking-off of negotiations. Instead, they involve parties agreeing to a regulation by claiming exceptions for themselves. ${ }^{72}$ Again, this strategy can considerably weaken the agreement's effectiveness, especially if the exception is granted to a major contributor to the problem. However, much like the modification strategy discussed above, it is useful in getting states to agree to an initial agreement, which later may be encouraged to 'fall forward' towards stronger arrangements. 
The exit strategy was used as part of the Soviet Union's negotiation strategy towards the 1985 Helsinki Protocol to the Convention on Long-Range Transboundary Air Pollution on Sulfur Oxides. While the Soviet Union planned to take an active role in the convention, it was not concerned with acid rain. Therefore, the Soviets devised a strategic plan for doing so at the least possible cost. They avidly negotiated for themselves a requirement to reduce not total emissions, as everyone else did, but only transborder flows of these emissions. As the Soviet Union had such a huge landmass and prevailing winds blew east, only about 3 to 4 percent of its sulfur emissions cross national borders. The Soviet Union could then comply with the Helsinki Protocol by shifting a small part of its energy production eastwards, so that the winds would no longer carry these emissions across Europe. ${ }^{73}$ In this case, the exception granted to the Soviet Union weakened the overall agreement, as it did not effectively reduce overall sulfur emissions originating from that state.

Another well-known example of the use of exit strategy is in the United Nations Framework Convention on Climate Change and its related Kyoto Protocol where many developing states acceded to the Convention under the condition that they would be, at least for the time being, exempted from any binding targets (Non-Annex 1 states). This would seem a more effective use of the exit strategy because while these states are exempted from binding targets, their accession meant that Annex 1 states are encouraged to engage them in emissions reduction measures through the Clean Development Mechanism (CDM). ${ }^{74}$

\section{Compensation Strategies in Negotiations}

The third tradeoff strategy is compensation. Compensation involves "creating a positive-sum agreement, by constituting elements evaluated differently by the parties...to enlarge the pie"; 75 in other words, to "multiply gains in order to make parties better off."" This type of tradeoff is popularly adopted within integrative approaches to negotiation, particularly among negotiators with the altruistic or cooperative behavioural style. These negotiators try to look for ways to create value, and expand the pie for the opponent states. 
The compensation strategy is commonly used to encourage accession in issues which involve asymmetric states. Zartman explains that usually, if proponents to the regulation are quite open to the legitimacy ${ }^{77}$ of the other party's concerns in the subject, they will be happier to agree to tradeoffs to achieve their own purposes. Hence, such states who feel burdened or taken advantage of by certain restrictions are given incentives to agree to the regulation in exchange for compensations to them. ${ }^{78}$ Two types of compensation strategies commonly employed in international environmental negotiations are in the form of side-payments and linkages.

Firstly, compensatory transfers in the form of side-payments will be discussed. This usually involves transfers of benefits from one party to the other with the intention to help the latter group of states to achieve the means to cooperate. ${ }^{79}$ For example, a state or certain group of states may be encouraged to reduce a certain amount of pollution or emissions if it is compensated with a fair amount by other states for its efforts. This strategy attempts to maintain the 'fairness' of agreements, by compensating certain parties for the incremental costs of implementing obligations under these regulations. ${ }^{80}$

In such negotiations, each side will usually have a reservation point, or 'bottom line' beyond which a party will break off from negotiation. The reservation point is closely related to each party's incentive structure, pertaining to the costs associated with each point of offer. If the amount of obligations that the compensated state is agreeable to adopt and the amount that the compensating state is agreeable to pay overlap, there exists a Zone of Possible Agreement (ZOPA) where positive-sum outcomes are possible (see Figure 2). An agreement in such cases is likely, and negotiators should be able to reach an accord at some point within this range. ${ }^{81}$

In negotiations for side-payments, it is important to consider the importance of a non-sovereign mediator. If the negotiations are state-led, either by the victim or source state, the other party may view such negotiations as tainted by the interests of the sovereign conductor. Also, as Maler argues, it is not very realistic to expect that both parties to have perfect information on each other's incentive structures, cost functions and reservation points. A home state that has imperfect information of the other party's incentive structures may be 
encouraged to cheat in order to improve its own benefits. This also may cause parties to arrive at unreasonable reservation points. Hence a non-sovereign mediator, from say an intergovernmental agency, would be useful in establishing a neutral environment where involved states would be encouraged to truthfully share both abatement costs and estimated benefits of controlling pollution, hence encouraging cooperation. This truth-telling will also help with the questions on how cost-sharing would work among victim states, and how to best allocate the proportion of waste discharge reduction among source states, if there are multiple source and victim states involved. ${ }^{82}$

\section{Figure 2: A Graphical Representation of $\mathrm{ZOPA}^{83}$}

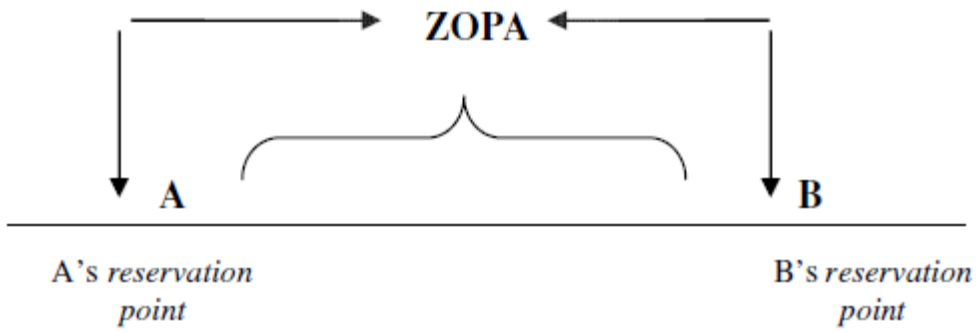

An example of this strategy at work is the 'Adopt-A-District' programmes between Indonesia, Malaysia and Singapore that were mediated by the Association of Southeast Asian Nations (ASEAN) in the attempt to address transboundary haze. Forest and land fires in upwind Indonesia were causing smoke haze pollution in downwind Malaysia and Singapore. The almost annual haze was costing Malaysia and Singapore millions in socioeconomic damages yearly. Therefore, these 'richer' states were willing to negotiate a deal that included monetary transfers to the 'poorer' Indonesia, in exchange for more concrete efforts in managing the haze. A ZOPA was found and these side-payments were used to assist Indonesia in capacity-building and community education to better prevent and manage such fires in coming years. ASEAN played an important mediating role in framing this arrangement within the parameters of the ASEAN Way, especially in terms of non-intervention, which was a major concern of Indonesia. 
On a larger scale, side-payments have also been a popular strategy in many North-South environmental negotiations. In these cases, side-payments transferring from the North to the South have been a useful way to increase the ability of Southern states to comply with agreements, and also to offset perceived free-riding by the North as a result of environmental sacrifices made by Southern states. ${ }^{84}$ The United Nations Collaborative Programme on Reducing Emissions from Deforestation and Forest Degradation in Developing States (UN-REDD+) is a good example of this strategy. Deforestation and forest degradation in developing states have been identified as a major source of carbon emissions that exacerbates climate change worldwide. However, forest use is an important engine of the economies of these Southern states. Hence, certain Northern states have offered to engage in monetary transfers to the affected Southern states in exchange for a certain degree of reduction in deforestation and forest degradation. This transfer of funds is meant to offset some of the costs and economic sacrifices that will have to be made in the process of reducing deforestation and forest degradation, which in theory would better enable these states to reduce their carbon emissions along the lines of the Kyoto Protocol to the United Nations Framework Convention on Climate Change. ${ }^{85}$

The second type of compensatory transfer is in the form of linkages. Using linkages in negotiations involve the linking of a Prisoner's Dilemma game to a mirror-image game, where the gains and losses are reversed. In this situation, the potentially defecting player will be engaged in another game with the same players, where it now needs the cooperation of the other players. To reap the gains of the latter game, players are compelled to cooperate in both games, creating a symmetric Prisoner's Dilemma. One way to achieve this is by negotiating, in addition to the original agreement, another agreement which increases spillover effects (for example, R\&D or trade preferences) only among cooperating states. ${ }^{86}$ International environmental negotiations that have observed this strategy of linkages include the Washington Convention on International Trade of Endangered Species (CITES) of 1975 and the Basel Convention on Hazardous Wastes of 1989, both of which managed to negotiate a wider participant coverage by encouraging nonparties to ratify in order to also enjoy trade benefits. ${ }^{87}$ 


\section{POLITICAL ECONOMY ISSUES IN NEGOTIATION}

Using trade benefits as a negotiation strategy is however controversial, as it is considered by some as a drastic interference with international trade. ${ }^{88}$ On the other hand, many scholars foresee that without such trade interference, environmental well-being will only worsen. While trade liberalization has been shown to largely succeed in raising incomes, these scholars have argued that this will only lead to more damage to the environment. ${ }^{89}$

The argument is that international free trade exacerbates the free-riding problem..$^{90}$ Free trade tends to increase world pollution and environmental damage by raising the scale of general economic activity. ${ }^{91}$ When some states have abatement policies that increase the costs to industry, it shifts comparative advantage in environmentallydamaging activity and pollution-intensive production towards the other states without such stringent abatement policies, ${ }^{92}$ in what is recognized as an environmental 'race to the bottom'. This then provides added incentives for damaging industries to locate in states with low environmental standards. ${ }^{93}$ Output of these damaging goods should therefore rise in these states, as should emissions. This increase in emissions as a result of this is known as 'leakage'. ${ }^{94}$

The problem of leakages can be avoided if such environmental distortions can be corrected or internalized at the national level. Trade restrictions for non-signatories have indeed been used as a negotiation strategy in IEAs to avoid such leakages. These trade restrictions are meant to cancel out any competitive advantage in trade with states might gain from abstaining the IEAs. This would reduce the gains available to these states as a result of free-riding, and if the restrictions are heavy enough, states may find it more beneficial to cooperate. ${ }^{95}$ Importantly, it is not the restriction in trade that should sustain cooperation but the credible threat to impose trade restrictions. ${ }^{96}$ Restrictions can include import tariffs or bans based on production process standards on imported goods, ${ }^{97}$ and additional requirements for non-signatories.

A good illustration of such restrictions imposed on nonsignatories is the CITES convention as discussed briefly above. CITES aims 'to prevent international trade in specimens of wild animals and plants from threatening the survival of the species in the wild'. 
The agreement includes guidelines for trade of these specimens with non-parties to the convention. It details that trade with non-parties is not permitted in the absence of documentation equivalent to a CITES permit. When faced with states have a record of non-compliance, CITES recommends that signatory parties 'take stricter domestic measures than those provided by the treaty, including complete prohibition of trade' against the offending state. Without these trade restrictions, it would continue to be profitable for the non-signatories to free ride on the conservation efforts of the signatories, while gaining competitive advantage over the trade of restricted species, which will increase for these states. It is interesting to note that in almost all cases, the offending state has come back into compliance or acceded to the convention $^{98}$ to reap the gains from trade, thus effectively cancelling out potential leakage.

Thus, such a strategy would be successful if parties are able to negotiate for wider participation in exchange for trade benefits, as were the cases with CITES and the Montreal Protocol on Substances that Deplete the Ozone Layer. Such restrictions were able to successfully act as a credible threat, as they were able to encourage full cooperation in environmental policymaking without diminishing the gains from trade. However, should negotiations fail to achieve universal or almost universal participation, these restrictions would deprive both signatories and non-signatories from some gains in trade, ${ }^{99}$ effectively punishing the signatories. Therefore, the outcome of this strategy may result in a lose-lose situation in terms of gains from trade, and reduce the overall effectiveness of agreed IEAs.

This has led some scholars to argue that when left to its own devices, free trade will actually have a positive effect on the environment. They point out that the national income gains brought about by freer trade will increase the demand for tougher environmental regulation and enforcement, make new investment in pollution abatement affordable, and generate government revenues for enforcement of environmental regulation. ${ }^{100}$ This is reflected famously in the environmental Kuznets curve, depicted in Figure 3. Hence, they argue that there is no need for trade restrictions linked to environmental policy. 
Figure 3: Environmental Kuznets Curve

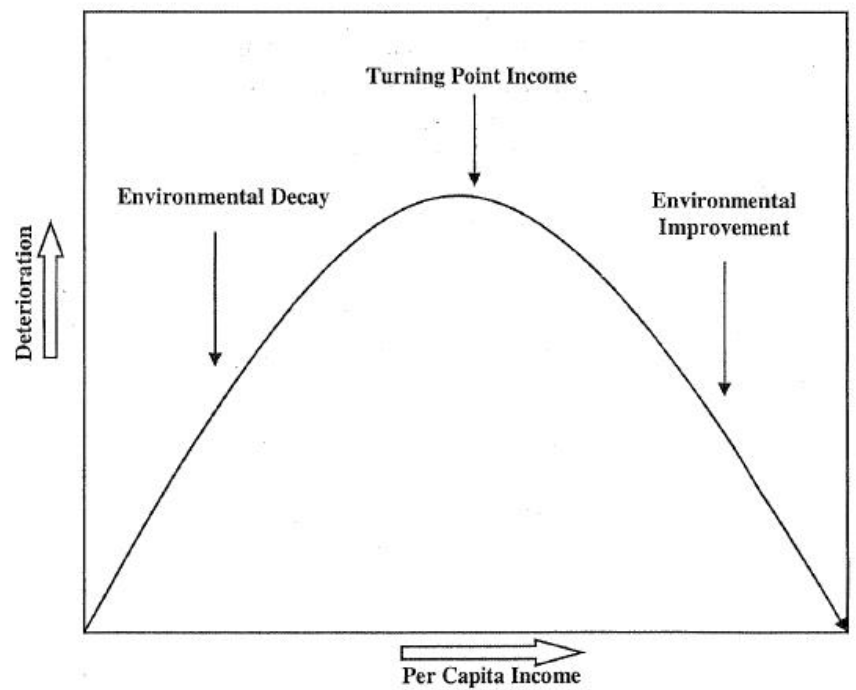

These arguments are the basis of GATT Article XX (and later carried forward into the WTO) that outlaws trade policy which is disguised as environmental policy. ${ }^{101}$ Such policies have been deemed to be inconsistent with the principle of non-discrimination in international trade. ${ }^{102}$ For example, process standards, with constraints based on the way a product is manufactured (and not regulations on the characteristics of the final product) would not accord equal treatment to like goods and would therefore most likely be found to be in violation of WTO rules. ${ }^{103}$ Hence, using trade benefits and restrictions as a negotiation strategy may be brought to question having too much of an interference with international trade ${ }^{104}$ and its regulations.

\section{CONCLUSION}

This paper has thus explored the theory and practice of international environmental negotiations towards IEAs for the better management of the world's shared resources. Importantly, several points must be given special note. First is the importance of international environmental negotiations in the management of shared resources. Scholars largely agree that most states will comply with most of their obligations most of the time. Therefore, IEA compliance is not the main issue in global environmental management. Rather, it is the process of designing agreements that states are happy to agree to sign and ratify or, in other 
words, international environmental negotiations. If negotiations can be carried out effectively, culminating in workable and effective IEAs, it is highly likely that obligations towards these IEAs will be carried out. Hence, understanding the negotiation process of such agreements is very important for managing the global environmental well-being.

Second is the importance of the negotiation process in bringing about a positive-sum outcome. While achieving zero-sum outcomes may be optimal in cases of competing interests, in the long run, this can result in lose-lose outcomes (even for the 'winning' party) when the agreement between different parties collapse if the losing side is no longer able or willing to maintain its side of the agreement. ${ }^{105}$ When states do not comply with agreements, the reason is often that they do not have the means to comply. ${ }^{106}$ Hence, even if one party is relatively more powerful than the others, it may not pay to take advantage of that power asymmetry in the long run. Instead, parties should strive to increase the will and ability of the opposing parties to maintain its side of the agreement through various tradeoff strategies to achieve an enduring and fruitful cooperative mechanism with maximum participation.

The third is the evolving nature of international environmental negotiations and IEAs. The various rounds and concessions involved in the negotiation process should serve to ensure the negotiator that if their interests were not satisfactorily met in this round, there will be opportunities to improve outcomes in later round. This evolving nature of IEAs 'keeps the options open' and should encourage negotiators to engage in tradeoffs (which can be recouped in later rounds), especially to increase participation in the early stages of international environmental negotiations. This should persuade negotiators to be more altruistic and cooperative in their negotiation behaviours and design a formula that 'falls forward' towards its own improvement with time.

Therefore, international environmental negotiations involve addressing the "means and motivations for bringing parties to the point of recognizing problems, seeking solutions and reconciling differences with other motivated parties." 107 As evidenced in the examples discussed throughout the paper, negotiation outcomes in reality are very rarely predetermined, despite asymmetric power distribution. 
Effective negotiation involves a combination of various approaches and strategies to arrive at positive-sum outcomes that enlarge the pie for all parties. Such international environmental negotiations should work towards arriving at IEAs that are satisfactory and within the capacity of all parties involved, which will increase the likelihood of all related obligations to be fulfilled in the long run.

\section{NOTES}

1 The author would like to express her appreciation to Dr. Euston Quah from Nanyang Technological University (NTU), Singapore, for his help and advice in the preparation of this paper.

2 Karl-Goran Maler, "International Environmental Problems," Oxford Review of Economic Policy, Vol. 6, No. 1, 1990, p. 88.

3 Ibid., p. 89.

4 In such cases, the choices faced by all states are binary; the states may Abate or Pollute. It is assumed that each state would prefer a larger payoff to a smaller one, but does not care about the payoff received by other states. However, the interdependence between the states is reflected in the fact that each state's payoff depends not only on its own action but also on what the other states do. In such scenarios, all states' best strategy is to Pollute, whatever the other states do. Therefore, because all states do not know what the other states are likely to choose, all states would chose to Pollute even though they would be better off if they abated their emissions instead, resulting in an inefficient outcome. See Scott Barrett, "Towards a theory of international environmental cooperation," in Carlo Carraro and Domenico Siniscalo (eds.), New Directions in the Economic Theory of the Environment, Cambridge: Cambridge University Press, 1997, p. 241.

5 Ibid.

6 Maler, "International Environmental Problems," p. 89.

7 Scott Barrett, "Self-Enforcing International Environmental Agreements," Oxford Economic Papers, Vol. 46, 1994, p. 878.

8 The decision to comply is usually endogenous to the negotiation stage. If the resulting treaty is shallow with minimum, non-costly obligations, compliance can be expected to be high, and no enforcement measures are needed (see James D. Fearon, "Bargaining, Enforcement, and International Cooperation," International Organization, Vol. 52, No. 2, 1998, p. 287). This of course does not always hold. For example, Canada was unable to respects its requirements to reduce its Greenhouse Gas emissions $6 \%$ below 1990 levels by 2012, and thus chose to withdraw from the Kyoto Protocol. 
This could possibly be related to an underlying issue during the negotiation stage, where Canada was unable to bargain for achievable targets. This article discusses precisely such issues; how states can be encouraged to agree to less shallow, more costly, but at the same time achievable obligations that would result in more effective agreements.

9 Abram Chayes and Antonia Handler Chayes, "Compliance Without Enforcement: State regulatory behaviour under regulatory treaties," Negotiation Journal, Vol. 7, 1991, p. 313.

10 Maler, "International Environmental Problems," p. 80.

11 "The ... inability of international regimes to mobilize formal sanctions and incentives does not mean that there are no penalties for non-compliance or benefits for compliance... members of a treaty regime have available a wide range of informal pressures and inducements to secure compliance with community norms. States have dealings and continuing relationships with each other over a range of issues. Questions of treaty compliance arise in an environment of diffuse reciprocity, with manifold opportunities for subtle expressions of displeasure, suspicion and reluctance to deal with treaty-violators in other contexts. A reputation of unreliability cannot be confined to the area of activity in which it is earned." See Chayes and Chayes, "Complaince Without Enforcement," p. 320.

12 Chayes and Chayes, "Complaince Without Enforcement," p. 320.

13 Barrett, "Towards a theory of international environmental cooperation," p. 253.

14 Chayes and Chayes, "Complaince Without Enforcement," p. 313-14.

15 Barrett, "Self-Enforcing International Environmental Agreements," p. 878.

16 Maler, "International Environmental Problems," p. 81.

17 I. William Zartman, "International Environmental Negotiation: Challenges for analysis and practise," Negotiation Journal April 1992, p. 114.

18 Maler, "International Environmental Problems," p. 80.

19 Ronald B. Mitchell, "Multilateral Environmental Agreements," International Environmental Agreements Database Project $<$ http://iea. uoregon.edu/images/Multilaterals.jpg>.

20 Zartman, "International Environmental Negotiation," p. 114-115.

${ }^{21}$ Tanya Alfredson and Azeta Cungu', Negotiation Theory and Practice: A review of the literature, Rome: Food and Agricultural Organization of the United Nations, 2008, p. 16.

${ }^{22}$ Zartman, "International Environmental Negotiation," p. 115.

23 Ibid., pp. 114-115.

24 Ibid., p. 115. 
25 Pamela Chasek, "A Comparative Analysis of Multilateral Environmental Negotiations," Group Decision and Negotiation, Vol. 6, 1997, pp. 439-440. 26 Defined commonly as "a specific community of experts sharing a belief in a common set of cause-and-effect relationships as well as common values to which policies governing these relationships will be applied." (see Peter M. Haas, "Do Regimes Matter? Epistemic Communities and Mediterranean Pollution Control," International Organization, Vol. 43, No. 3, 1989, p. 384)

27 Zartman, "International Environmental Negotiation," p. 119.

28 Maler, "International Environmental Problems," p. 100.

29 Stephen L. Kass and Jean M. McCarroll, "Environmental Law," New York Law Journal, Vol. 26, No. 3, October 2004.

30 Maler, "International Environmental Problems," pp. 100-101.

31 Alfredson and Cungu', Negotiation Theory and Practise, p. 6.

32 Zartman, "International Environmental Negotiation," p. 115.

33 Alfredson and Cungu', Negotiation Theory and Practise, p. 16.

34 Chasek, "A Comparative Analysis of Multilateral Environmental Negotiations," pp. 439-440.

35 Zartman, "International Environmental Negotiation," p. 120.

36 Chasek, "A Comparative Analysis of Multilateral Environmental Negotiations," pp. 439-440.

37 Zartman, "International Environmental Negotiation," p. 113.

38 Ibid., p. 120.

39 Alfredson and Cungu', Negotiation Theory and Practise, p. 14.

40 Maler, "International Environmental Problems," p. 80.

41 Alfredson and Cungu', Negotiation Theory and Practise, p. 25.

42 Ibid., p. 14-15; Zartman, "International Environmental Negotiation," p. 116.

43 Zartman, "International Environmental Negotiation," pp. 116-117.

44 Ibid., p. 116.

45 Ibid., pp. 116-117.

46 Chasek, "A Comparative Analysis of Multilateral Environmental Negotiations," pp. 437.

47 Alfredson and Cungu', Negotiation Theory and Practise, p. 6; Zartman, "International Environmental Negotiation," p. 120.

48 Zartman, "International Environmental Negotiation," p. 114.

49 Alfredson and Cungu', Negotiation Theory and Practise, p. 9; Zartman, "International Environmental Negotiation," p. 114.

50 Ibid., p. 7-9.

51 Ibid., p. 11. 


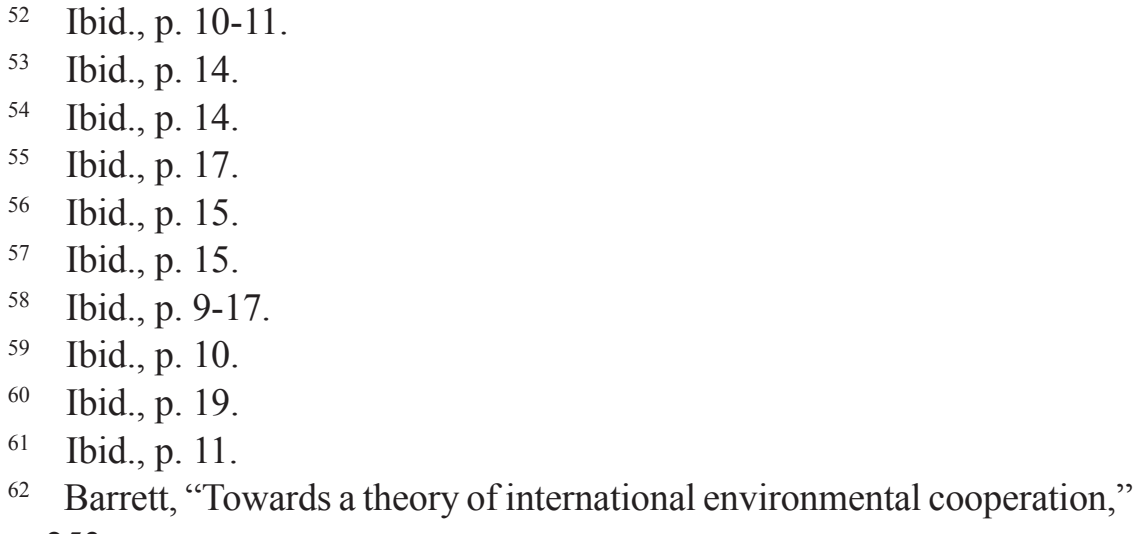
p. 253.

63 Zartman, "International Environmental Negotiation," pp. 120-121.

64 Barrett, "Towards a theory of international environmental cooperation," p. 253.

65 Barrett, "Self-Enforcing International Environmental Agreements," p. 878.

66 Zartman, "International Environmental Negotiation," p. 118.

67 Ibid., pp. 118-121.

68 Kass and McCarroll, "Environmental Law."; John H. Knox, "The Myth and Reality of Transboundary Environmental Impact Assessment," The American Journal of International Law, Vol. 96, No. 2, 2002, p. 297.

69 Knox, "The Myth and Reality of Transboundary Environmental Impact Assessment," p. 297.

70 This principle would be along the lines of Principle 21 in the Stockholm Declaration, that states have the responsibility to ensure the activities within their jurisdiction or control do not cause damage to the environment of other states or of areas beyond the limits of national jurisdiction. This principle enjoys substantial popularity within environmental negotiations, and has been included in various treaties related to the use of common property resources, for example those governing the use of shared waterways like the Niger in 1980 and the Rhine in 1986 (see Maler, "International Environmental Problems," pp. 82-83).

71 Knox, "The Myth and Reality of Transboundary Environmental Impact Assessment," p. 296.

72 Zartman, "International Environmental Negotiation,” pp. 120-121.

73 Marc A. Levy, "European Acid Rain: The Power of Tote-Board Diplomacy," in Peter M. Haas, Robert E. Keohane and Marc A. Levy (ed.), Institutions for the Earth: Sources of Effective International Environmental Protection, Massachusets: MIT Press, p. 123. 
74 The CDM allows a country with an emission-reduction or emissionlimitation commitment under the Kyoto Protocol (Annex B Party) to implement an emission-reduction project in developing countries. Such projects can earn saleable certified emission reduction (CER) credits, each equivalent to one tonne of $\mathrm{CO}$, which can be counted towards meeting Kyoto targets. A CDM project activity might involve, for example, a rural electrification project using solar panels or the installation of more energyefficient boilers. The mechanism stimulates sustainable development and emission reductions, while giving industrialized countries some flexibility in how they meet their emission reduction or limitation target (see United Nations Framework Convention on Climate Change).

75 Zartman, "International Environmental Negotiation," p. 117.

76 Alfredson and Cungu', Negotiation Theory and Practise, p. 7.

77 Truth-telling would hence become profitable (see Maler, "International Environmental Problems," p. 86) to the party that seeks to convince the proponent that it has legitimate concerns (like economic or developmental burden, or the state being a victim of free-riding by other parties), and is not trying to avoid its obligations while at the same time enjoying the gains of a public good (see Zartman, "International Environmental Negotiation," p. 118). At once, the problem of incomplete information will also be reduced (see Maler, "International Environmental Problems," p. 86). When the other party's concerns are no longer seen as selfish or interest-related, the proponent will be more willing to engage in tradeoffs to alleviate these burdens.

78 Zartman, "International Environmental Negotiation," p. 121.

79 Ibid., pp. 117-118.

80 Barrett, "Towards a theory of international environmental cooperation," pp. 273-274.

81 Alfredson and Cungu', Negotiation Theory and Practise, p. 8.

82 Maler, "International Environmental Problems," p. 85.

83 Ibid., p. 8.

84 Zartman, "International Environmental Negotiation," pp. 117-118.

85 However, a continued concern with transfers to Southern states is corruption. Northern states are often concerned how much of their monetary transfers genuinely reach the projects and people targeted. Norway's UNREDD+ contributions in Indonesia was argued to be less than effective as the trickle-down rate of these funds was very low (see Helena Varkkey, "Oil Palm Plantations and Transboundary Haze: Patronage Networks and Land Licensing in Indonesia's Peatlands," Wetlands, Vol. 33).

${ }^{86}$ Barrett, "Towards a theory of international environmental cooperation," p. 268. 
87 Zartman, "International Environmental Negotiation," p. 117.

88 Ken Belcher, "Trade Agreements and Multilateral Environmental Agreements," in William Alexander Kerr and James D. Gaisford (eds.), Handbook on International Trade Policy, Massachusets: Edward Elgar Publishing, Inc., 1997, p. 432.

89 Brian R. Copeland and M. Scott Taylor, "Trade and Transboundary Pollution," The American Economic Review, Vol. 85, No. 4, 1995, p. 716. 90 Barrett, "Towards a theory of international environmental cooperation," p. 269.

91 Copeland and Taylor, "Trade and Transboundary Pollution," p. 716.

92 Barrett, "Towards a theory of international environmental cooperation," p. 269.

93 Copeland and Taylor, "Trade and Transboundary Pollution," p. 716.

94 Barrett, "Towards a theory of international environmental cooperation," p. 269.

95 Ibid., p. 269; Belcher, "Trade Agreements and Multilateral Environmental Agreements," p. 432.

96 Barrett, "Towards a theory of international environmental cooperation," p. 272.

97 Rodney D. Ludema and Ian Wooton, "Cross-border externalities and trade liberalization: the strategic control of pollution," The Canadian Journal of Economics, Vol. 27, No. 4, 1994, p. 952.

98 Belcher, "Trade Agreements and Multilateral Environmental Agreements," p. 432.

99 Barrett, "Towards a theory of international environmental cooperation," p. 270-272.

${ }^{100}$ Copeland and Taylor, “Trade and Transboundary Pollution,” p. 716.

101 Ibid., p. 733.

102 Ludema and Wooton, "Cross-border externalities and trade liberalization," pp. 952-953

${ }^{103}$ Ibid., p. 961.

${ }^{104}$ Belcher, "Trade Agreements and Multilateral Environmental Agreements," p. 432.

${ }^{105}$ Alfredson and Cungu', Negotiation Theory and Practise, p. 10.

${ }^{106}$ Barrett, "Towards a theory of international environmental cooperation," p. 253.

107 Zartman, "International Environmental Negotiation,” p. 114. 